been a key strand of Prospect Hospice's work for more than a decade and, more recently, the hospice's Board of Trustees have sought recognition for the excellence of the standard of education and training offered there.

Aims Specifically, the Board of Trustees felt strongly that the education team should offer accredited courses, and achieve external recognition for the standard of our education offering.

Methods A new role of Education Manager was created to supplement the Education Facilitator and Administrator in the team. This role was recruited to swiftly, and the new manager approached a range of accreditation bodies, from which the NCFE was chosen. NCFE had recognised that Prospect Hospice had limited resources as a charity whose funding was predominantly raised through the local community. The Education Manager then compiled a 'centre folder' of policies and procedures to demonstrate high standards of teaching and quality assurance at Prospect Hospice.

Concurrently the Education Manager looked into the Skills for Health (SfH) Quality Mark scheme, creating a portfolio of evidence to demonstrate outstanding delivery of learning and training from the education team to support a highly motivated and effective workforce. Following the submission of this, two $\mathrm{SfH}$ assessors reviewed paperwork, interviewed trainers and learners and observed teaching to benchmark Prospect Hospice's standards with their own.

Results In August 2016 Prospect Hospice became an approved NCFE education and training centre for its courses. In March 2017 Prospect Hospice became the first fully independent hospice to achieve the Skills for Health Quality Mark. These results were achieved within nine months of the Board of Trustees' request.

\section{P-253 EDUCATOR AMNESTY! DEVELOPMENT OF A NETWORK SPECIALIST PALLIATIVE CARE EDUCATOR DEVELOPMENT PROGRAMME}

\begin{abstract}
1,2Karen Groves, ${ }^{2,3}$ Salli Jeynes, ${ }^{4}$ Sharon Phillips, ${ }^{3}$ Vanessa Shaw, ${ }^{5,6}$ Jan Howard, ${ }^{1}$ Cathy Godfrey. 'Queenscourt Hospice, Southport, UK; ${ }^{2}$ Cheshire and Merseyside Palliative and End of LIfe Care Network, UK; ${ }^{3}$ End of Life Care Partnership, Cheshire, UK; ${ }^{4}$ Marie Curie Palliative Care Institute, Liverpool, UK; ${ }^{5}$ Queenscourt Hospice, Southport, UK; ${ }^{6}$ Liverpool Marie Curie Institute, UK
\end{abstract}

\subsection{6/bmjspcare-2017-hospice.278}

Background In 2014, 322 specialist palliative care (SPC) professionals responded to a network education strategy group (ESG) workforce scoping exercise. The majority spent at least $10 \%-20 \%$ of their time educating, $70 \%$ in clinical front-facing areas or at point of care, rather than from, or in, education centres, providing academic courses or online learning. Preparation for educating experienced by the majority was observation/experience $(12 \%)$ or ENB 998 course, single module or Train the Trainer courses (30\%-40\%). Less than 10\% had educational qualifications.

Approach Six main challenges for educators were identified educating peers and those perceived to be higher in professional hierarchy; managing personalities; lack of knowledge of best practice in supporting adult learning; cultural differences; developing by teaching with others; lack of peer review. A successful bid for Multiprofessional Training and Education Monies (MPET) funded the three education centres to design, develop and deliver the programme, for three cohorts each, over a two year period, and an independent research evaluation.

Results Educators from across the network worked together to develop a bespoke Educator Development Programme (EDP) to address the expressed needs and challenges of all (273) SPC professionals who did not already have educational qualifications or a development pathway in place and yet may have been teaching as part of their role, for a number of years. Doctors were excluded as separate funded mechanisms are already in place for formally training and recognising medical teachers.

Conclusions EDP was designed as three modules, addressing each of 'one to one', 'small group' and 'formal' teaching; delivered over a period of one year to allow time for practice, reflection, peer review and mentorship; to increase knowledge, skills and confidence. This poster describes the development process and design.

\section{P-254 EMBEDDING THE CARE CERTIFICATE INTO CLINICAL APPRENTICESHIPS}

Mandy Motley, Donna Walker. LOROS Hospice, Leicester, UK

\subsection{6/bmjspcare-2017-hospice. 279}

Background Following the Francis Review, Camilla Cavendish carried out a review of support workers and health care assistants across health and social care. Her recommendations formed the basis of the Care Certificate which was formally launched on 1 April 2015, and required all new health care assistant and social care staff to achieve the Care Certificate in 12 weeks of commencing employment. At LOROS we introduced a new post into the organisation, Assistant Practitioner (AP), to support the development of the non-registered staff and to lead the implementation of the care certificate across the hospice.

Aims Our aim was to develop a robust programme which not only ensured new healthcare assistants achieved the Care Certificate, but also provided valid evidence to support those staff who were also undertaking a healthcare apprenticeship.

Methods A programme of training and education has been developed which ensures all knowledge and skills required for their role are covered. This entails a presentation for all of the 15 standards with resources drawn from both the Skills for Health website and organisational specific information. The AP has completed the CAVA award which enabled her to ensure the assessment of the student work covered the learning outcomes for both the care certificate and the apprenticeship diploma. There is regular partnership working between the AP and the assessor from college, including joint standardisation meetings.

Results All new healthcare assistants achieve their care certificate in a timely fashion, and those on an apprenticeship are able to map the evidence for up to $30 \%$ of their diploma. Apprentices who have achieved their apprenticeships have secured permanent employment at the hospice.

Conclusion The dedicated role within the organisation to support this initiative with an appropriately qualified member of staff, working closely with the college has ensured the success of this approach. 